\title{
Methodical Errors of the SWOT-Analysis in Applied Research
}

\author{
Aleksey Murzinov ${ }^{1}$, and Tatiana Zhubreva, ${ }^{1, *}$ \\ ${ }^{1}$ Moscow Technological Institute, 199334, Moscow, Russia
}

\begin{abstract}
The article discusses the methodology is widely known the SWOT-analysis and suggests approaches to increase confidence in the results of the analysis. Some typical methodological errors are Illustrated by examples and discussed. Recommendations that increase the value of the method in strategic analysis and increase its effectiveness are given. The recommendations could be useful for companies' managers of different levels in the strategy development and advancement of strategic alternatives, Diploma Thesis supervisors as well as for students and graduates of MBA programs.
\end{abstract}

\section{Introduction}

One of the most widely known methods of strategic analysis - SWOT analysis - has found wide application in practice of development planning of enterprises into various fields of business. However, not everyone who uses this method, familiar with the intricacies of filling in the 'magic squares', designed to ensure business prosperity of a company or an enterprise.

Methodically incorrect application of the method at best generates distrust to the analysis and its results, and at worst leads to incorrect conclusions.

Considerable experience of the authors in the application of the SWOT analysis and generalization of the other researchers' experience allows identifying the main methodological errors, which occur in the analysis process, including when it is done as a part of business research in the frame of Diploma Thesis preparation in the MBA programs.

\section{Literature Review}

\subsection{The basic principles of SWOT analysis}

The methodology of the SWOT-analysis is seemingly simple to use. The essence of the analysis is to perform sequential steps: identification of favorable and unfavorable factors of the external and internal environment, formulation of the list of main opportunities and threats offered by the external environment, strengths and weaknesses that characterize the company. The mapping of internal and external factors follows this $[1,2]$.

However, the implementation of this methodology in practice leads to the fact that "the output is a mess of randomly-chosen insights and factors that is why proposals based on them become unreliable and light weighted" [3]. The main reason usually is the incorrect interpretation of external and internal factors, methodically incorrect 'binding' of various factors to a particular company. In sufficiently detailed manner the methodological characteristics identifying essential factors in the external environment when developing strategy according to the methodology of SWOT analysis are described in the articles $[4,5]$.

\subsection{The main causes of methodological mistakes in SWOT analysis}

One of the main reasons of methodological errors is the subjectivity of the analysis, the prevalence of the intuitive approach to the extension of favorable and unfavorable factors on the analytical methods for their detection. A widespread approach that involves the identification of favorable or unfavorable factors in the external environment and the identification of opinions about the strength and weaknesses of the company with the help of managers (working with the analyzed company) through individual surveys or discussion groups is not tenable. Manager's judgment about the company and its environment could be important, but employees do not always comprehend the real, based on facts, situation. Mostly often, their judgments are rather subjective. In addition, practice shows that employees of the company, even if they know the ins and outs of the business, are not always willing publicly disclose it.

As a result staff opinions may contain "nuggets of gold, but mixed with a fair amount of gangue and inclusions, just looking like gold, which often leads away from the solution of the task facing him. Naturally, such an outcome is not inevitable, but it's a strong possibility" [3].

\footnotetext{
*Corresponding author: tjoubreva@mti.edu.ru
} 
To reduce the influence of subjective judgment, both external and internal factors should be identified on a rational basis. With this purpose, one should use a few key ways to determine the true external and internal factors influencing the company's operations, its success in the short and long term.

These include:

- Secondary data review;

- Expert survey;

- Investigations and experiments.

\section{Research Methods}

To identify the causes of systematic errors when conducting a SWOT analysis the research was conducted within the phenomenological paradigm related to the understanding of human behavior within this paradigm "...social reality depends on the mind" $[6$, p. 53] of the participants; the studied phenomenon and the researcher cannot be separated from each other.

To find the ways for increasing the level of the SWOT analysis validity analytical qualitative approach to the research was used, as according to this methodology, "the researcher goes beyond describing the characteristics of analyzing and explaining why and how it occurs" [6, p. 11].

General population includes the SWOT analyses prepared in the process of the consulting activities of the authors, and also those that had been presented in Diploma Thesis of MBSH students ("distance education with a tutor taking an active role" [7]) for the past 3 years. The final papers were those where MBSH tutors performed the role of academic supervisors. In a random sample, there were students and graduates, who applied for advice and assistance when conducting a SWOT analysis in the framework of their professional activities. Bough are classified as primary data $[6,8]$.

\section{Findings}

\subsection{Generalization of secondary data when conducting a SWOT analysis}

Information and analytical data published in the media and Internet, as well as data from the analyzed companies are a good source of necessary information. The information gleaned from publications, can be very useful. Especially if these data or overviews presented by well-known political scientists, economists, analytical agencies. However, this information suffers from redundancy; opinions are often inconsistent, and sometimes biased. There is another difficulty when working with secondary information: all information from secondary sources, including statistical materials, is created for specific purposes, and for the purposes of the second researcher could be useful only in part. For this reason, the study of secondary information is obligatory, but not sufficient method to obtain objective data. The best results could be obtained only after consideration of the information gathered from the experts.

In other words, to reduce the subjectivity in identifying the factors it is advisable to pre-assemble factual material on the analysis of the external and internal environment, not limited to the fixation of certain opinions of the company employees.

\subsection{Identification and synthesis of expert opinions}

The method provides the most objectivity in the identification and estimation, since the experts are the most knowledgeable people. The main difficulty lies in the selection of people, whom we could rightly call experts. Given that companies for a number of reasons are the most often orientated on their own employees, people with expert knowledge on all aspects of analysis are difficult to find. Therefore, before conducting, the expert survey should prepare the relevant data and to allow the persons involved in the evaluation, to be acquainted with the available secondary information. Furthermore, expert evaluations are usually unequal; in any case, you should pay attention to the consistency of expert opinions (defined by the coefficient of concordance of Kendall). These features require us to conduct expert interviews on procedure, contributing to increase the objectivity of the results [9].

\subsection{Investigations and experiments}

In many cases, for identifying environmental factors it is necessary to carry out primary investigation among customers and competitors. In this case, people use such methods as focus groups, surveys, and benchmarking. In the case of the internal environment analysis researchers use applied methods of analysis of financial and economic activities, methods of personnel analysis, including, where appropriate, and questionnaires.

Each of these ways has advantages and disadvantages, so they are used in combination. In other words, the detection (identification) of external and internal factors and their assessment should be based on facts. Judgments and personal assessments of facts could still take some place, but only on the stage of a comparison of the facts.

Factors are relative, relative to vision and goals. Favorable and unfavorable factors of the external environment, as well as the strengths and weaknesses of the company do not have absolute values. The event, phenomenon in the external environment can carry the threat for one company, and create a rare opportunity for others. Similarly, strengths and weaknesses are relative. Depending on the purposes of different companies, even operating in the same market, these companies can consider the same factors as strong for one and weak for other ones.

This means that there is no absolute strong and weak points, they are relative in relation to the objectives of the company and to the context in which the entity 
operates. For example, strengths and weaknesses will help or hinder the achievement of specific vision and strategy. Upon changing the strategy, strengths might lose their importance, and the weaknesses gain strength. Similarly, external opportunities and threats are important in the certain situation. It is considered that the external factors act on the company throughout the industry. Do so, however, the influence for each specific company is very concrete since the possible consequences are different.

In this regard, the detection and evaluation of both external and internal factors for SWOT analysis should focus on the vision and goals of the company and the context in which the company exists, especially to competitors. You should to compare the performance of the company with the efficiency of other companies in the same industry or to the average efficiency in the industry.

\subsection{Identify the factors in a systematic manner}

The widely used algorithm of SWOT analysis is based on identifying external and internal factors based on the experience and knowledge of the employees. As a rule, this leads to unsystematic, random appearance factors. Very often, important for company characteristics of external environment or a substantial parts of the company remain without attention. The company even related to small businesses, are economic system, the elements of which are closely linked, moreover, they are part of a more general economic system. Therefore, the company should be considered systematically and identification of the factors should be conducted on a systematic basis. Moreover, the identification of factors must be undertaken using a methodological approach that would allow identifying the maximum number of factors that affect the company in all spheres of activities. I.e. systematically and consistently, considering the company and its environment from all the sides.

Among the most common methods for systematic search of the external environment factors researchers use PESTEL analysis and 5FP (analysis five forces of Porter). When searching for the internal factors the most popular approaches are such as Porter's value chain and managerial examinations, which consider all aspects of the company activities.

External factors are events. As external factors (opportunities and threats) there should be used events, phenomena, and trends that characterize the external environment and are for the company either favorable (comfortable) or unfavorable factor. Opportunities and threats exist in the external environment regardless of the object of study. As a rule, in practice, external factors that characterizes the 'threats' are formulated correctly. Threats always come from outside. Errors occur in the formulation of 'opportunities'.

This is due to the perception of the word 'opportunity', which is mentally formulated as "I, we, can do this or that, we have the opportunity". At the same time, 'opportunities' in SWOT analysis are factors that operated in the external environment, and regardless of the object of consideration that can contribute (create) opportunities. To avoid that conflict we recommend in Russian language using the definition 'favorable external factors' instead of 'opportunities' that will reduce the number of errors.

When identifying the environmental factors it should be noted another circumstance. Quite often an external factor, the researchers use the qualitative characteristics of the environment or the description of the situation. For example, 'bad (good) economic situation in the country' or 'favorable / unfavorable investment climate'. To characterize the situation in such a way is just enough to watch a news program on TV. However, the situation is a product of a plurality of events, so it is a blurred concept. The impact of the situation on the company includes a significant touch of uncertainty. It is rather difficult to identify clear causal relationships. At the same time, the situation is the sum of events and generates event [10]. These particular events have more or less clear cause and affect companies.

For example, another analogy, based on natural events. "The clouds had gathered over the city, the air smells of a storm" (the words from Mark Bernes song) this is a situation. However, this means that soon it will rain and storm (expected event). That is precisely an approaching storm, which will bring heavy rainfall and may cause damage to both population and the city itself. Similarly, when fulfilling the analysis of the external environment, one should take as external factors not the situation but the event. The event occurs with a certain probability and leads to certain consequences. The situation has a general impact, it is some background, and the specific event caused by this situation has a direct impact. To quantify the situation is extremely difficult, and not necessary, but events can bring direct measurable damage or create a specific (concrete) opportunity. By the way, in risk management exactly the event is concerned as a risk.

Another circumstance worthy of consideration. Without exception, all the researchers use the data characterizing the state of a particular segment of the external environment. For example, evaluating the degree of importance of external environment factors on the enterprise for the production of feminine hygiene, the researchers used such 'factors' as the level of inflation, fall in GDP, decreasing of oil prices, devaluation of the local currency, and the credit rating of the country.

All the listed above parameters, undoubtedly, characterize the economy of the country. At the same time, the economy affects the enterprise manufacturing personal products of feminine hygiene, nevertheless, as other companies in other industries. However, these parameters characterize the situation in the economy and are very important for macroeconomic planning, but none could assess this impact to a specific company. If to omit the chain of causality, the poor state of the economy leads eventually to a drop in living standards and a drop in demand or a shift in demand to cheaper products. Decline in demand, as an external factor affecting the particular company, is much easier to assess than the impact of the macroeconomic indicators. 
The situation is an uncertainty, in the sense that the description of the situation contains no information about probable future events, that is, the situation is not amenable to evaluation. With the exception of the dynamic situations. If the situation changes for better or worse, this is trend (a sequence of unidirectional events). If we have identified a trend, we can expect the next event matching this trend. The impact of this event could be easily traced. Therefore, the situation leads to events; events exactly affect a company. They have to find events and use them as external factors.

Internal factors are resources and capabilities. Internal strengths and weaknesses of the company one should search among the resources and abilities that it has. Resources could be material, nonmaterial, and human resources.

However, a variety of resources owned by the company can be considered as its strong point, which may lead to competitive advantage only if the company has the organizational abilities (core competencies) in the usage of these resources. The mere existence of resources does not guarantee victory in the competition. Companies have to dispose these resources adequately [11]. Capabilities hierarchy. In business, processes of companies have the form of nested dolls. The high-level processes consist of a series of processes on a lower level, you can draw them as 'a tree model of business processes' or as business processes network. Similarly, the capabilities of the company can be divided into general and functional, and specialized skills and abilities of a lower level. In other words, the general capabilities of the company, which are determined for the whole company, are the result of the integration of functional and specialized abilities of the lower level.

As an example, consider the key ability of "Scientific center of cardiovascular surgery named after A. N. Bakulev": the ability of the Centre to treat cardiovascular disease. This ability is determined by the integration capacities of the center in the delivery of patient diagnosis, surgery, preparation of patient for surgery and providing him/her post-operative care, and many other abilities. In the formation of this ability, the effectiveness of support services and administration play role.

Functional capabilities include a number of specialized abilities, providing separate tasks accomplishing. The top-level capabilities require the implementation of cross-functional integration. For example, the ability to develop new products requires the integration of $\mathrm{R} \& \mathrm{D}$, marketing, strategic planning, operations and finance. A key capacity for innovative development of new products, which is common for many companies, is the abilities integration to analyze the market situation, the organization of research and experimental activities, identifying the best forms of commercialization, etc. Unique in this sense, is the $3 \mathrm{M}$ Company. For $3 \mathrm{M}$, this key ability (the ability to develop new products and related functions) and 3M's capability in new product introduction have been maintained over several generations of employees [12].

It must be emphasized that very often in the literature, especially in the Internet publications; they suggest using the estimated company's activities in particular functional areas as the strengths and weaknesses of that company. For example, the strategy is strong or weak, finances are strong or weak, the staff is qualified or not qualified, etc. Such a generalized notion of strong and weak sides of the company for the purpose of strategic analysis is not valid. Strong (Strengths) and weak (Weaknesses) this is not a general assessment of the company, but its specific characteristics (resources and abilities).

If the company made a clear, definite, understandable, effective, feasible, and shared by all stakeholders' strategy, it is indisputable plus of the company. However, a strong side in this case is the ability (in this case ability as a resource) for strategic analysis and choosing of the appropriate strategy. Moreover, this ability requires evidence. It is unlikely that after one developed strategy the company manages can brag about their potential for strategic planning.

There is no reason to consider the fact of the strategy existence as an important resource. The story is that strategy manages adopt at present time; the results of its execution will be visible only in the future, so in this future someone can boast that in the past the right strategy has been developed. At the same time, the absence of any strategy undoubtedly is the weak side of the company.

In general, the assessment of the overall financial condition of the company for the purpose of strategic analysis is also not suitable. It is important for the analysis the existence of the source for innovations and development activities financing. Therefore, strong sides for the purpose of strategic analysis include the availability of retained earnings, access to cheaper resources, or the ability of the company financiers to find common language with creditors.

Personnel assessment cannot be one-sided. On one hand, it is the skills possessed by the staff, and on the other is the adaptability of the employees and their social skills (ability to work in a group). In addition, it is the responsibility and loyalty of employees. If the researchers for the purposes of strategic analysis declare that the company has qualified personnel, it means that their knowledge of staff is extremely low. Not the overall rating is important, for example, of personnel, but the identifying specific competence that could be put in the basis of strategy development.

Difficulties in understanding factors do not stop there. Very often, they argue that internal factors can present opportunities and threats for the company, so, they say analysts need to use not only the external opportunities and threats but internal opportunities and threats also. From the point of view of the Russian language is acceptable. For example, our company can expand markets or increase market share. There is such a possibility. Acceptable from the point of view of linguistic practice, but not acceptable from the point of view of logic laid down in the SWOT analysis. The company's ability to expand markets or increase market share, is not our strength, it is our desire, intention, goal in the end, based on available resources, experience and market needs. 


\section{Conclusions}

The synthesis of described in the literature experience of the SWOT analysis and discussed in this paper the results of conducting SWOT analysis in the process of counselling and tutoring activities of the authors, their supervising the Diploma Thesis of MDSH students allows to draw the following conclusions.

To eliminate the subjectivity of the analysis and the uncertainty of the results of the SWOT analysis everyone should identify external and internal factors systematically using the full procedure of the expert survey.

As external factors (opportunities and threats), is wise to use events, phenomena, and trends that characterize the external environment and represent favorable (comfortable) or unfavorable factors or the company. When determining the internal strengths and weakness of the company parties, it is important to understand that this is not a general assessment of the company, but characteristic of its specific features (resources and abilities).

\section{References}

1. K. Fleischer, B., Bensussan. Strategic and competitive analysis. Methods and tools for competitive analysis in the business (Moscow, BINOM, 2017)

2. 2. N. S. Otvarukhina, V. R. Vesnin. Contemporary strategic analysis (Moscow, Urait, 2016)
3. P. Jenster, D. Hussey. Analysis of the strengths and weaknesses of the company. Identification of strategic opportunity (Moscow, Williams, 2003)

4. A.V. Murzinov. Proc. 11 conf. Educational environment today and tomorrow, 302 (2016)

5. A.V. Murzinov. Proc. 11 conf. Educational environment today and tomorrow, 304 (2016)

6. J. Hussey, R. Hussey, Business Research. A practical Guide for Undergraduate and Postgrad. Students (Macmillan Press LTD, 1997)

7. T. Zhubreva, SHS Web of Conferences, 29, 02047 (2016)

8. D.R. Cooper, P.S. Schindler. Business Research Methods (Irwin/McGraw-Hill, 2001)

9. A.I. Orlov. Expert assessments (Moscow, 2002)

10. R.R. Popova, Bulletin of TGGPU. Series 1. Psychological and pedagogical Sciences, 25, 2011

11. R. Grant, M. Robert. Contemporary strategy analysis (John Wiley Sons Ltd, 2010)

12. M.H. Zack (Ed), Knowledge and Strategy (Butterworth-Heinemann, 2008)

13. O. Chapelle, V. Vapnik, O. Bousquet, S. Mukherjee, Machine Learning, 46, 131 (2002)

14. L. Yu, S. Wang, K. K. Lai, L. Zhou, Bio-Inspired Credit Risk Analysis. Computational Intelligence with Support Vector Machines (Springer, 2008) 